http://www.jfas.info

\title{
BREAKDOWN STRENGTH OF TRANSFORMER OIL FILLED WITH CARBON NANOTUBES UNDER VARIOUS GAP DISTANCES
}

\author{
N. S. Suhaimi ${ }^{*}$, M. T. Ishak, M. F. Din, M. M. Ariffin, S. Razali, N. A. Amin and F. R. \\ Hashim \\ Department of Electrical and Electronics, Faculty of Engineering, National Defence \\ University of Malaysia, Sg. Besi Camp, 57000 Kuala Lumpur, Malaysia
}

Published online: 10 September 2017

\begin{abstract}
A new class of colloidal insulating transformer oil is formulated by dispersing CNT nanomaterials with mineral oil in purpose to enhance the breakdown strength performance of existing transformer oil. This paper represents the experimental studied dealing with the influence of $\mathrm{CNT}$ nanomaterials mix with transformer mineral oil in term of AC breakdown voltage at various gap distances. The concentrations of CNT nanomaterials were measured in range $0.01 \mathrm{~g} / \mathrm{L}$ to $0.2 \mathrm{~g} / \mathrm{L}$. The impact of three gap distances $(1.5 \mathrm{~mm}, 2.5 \mathrm{~mm}$ and $3.5 \mathrm{~mm})$ for mushroom-mushroom electrode configuration is studied in order to observe and compare the trend between conventional mineral oil and CNT nanofluids. To employ CNTs as effective reinforcement in mineral oil, proper dispersion methods need to be applied.
\end{abstract}

Keywords: transformer; mineral oil; CNT; breakdown voltage; Weibull.

Author Correspondence, e-mail: sabrina15.eec@gmail.com

doi: http://dx.doi.org/10.4314/jfas.v9i3s.4

\section{INTRODUCTION}

The life expectancy and satisfactory operation of transformers are mainly depending on the transformer insulating oil. The mineral oil serves mainly with two purposes which are as 
insulation in transformer and another one as a coolant agent to remove heat from the windings. Recently, lots of studies have been done with purpose at enhancing the dielectric properties of insulating oil. The studies have been conducted to prove the efficiency of nanofluid by dispersing nanomaterials with based oil samples. There were various types of nanomaterials that have been investigated such as $\mathrm{TiO}_{2}, \mathrm{CeO}, \mathrm{Al}_{2} \mathrm{O}_{3}$ and others $[1-4,14]$. However, there are very constrained data regarding CNT nanomaterials.

A carbon nanotube (CNT) is a mysteriously fascinating material for a component of nano-suspension because of their unique structure and remarkable mechanical, thermal and electrical [5-7]. CNT renowned for conducted heat and cold very well, which mean it has high thermal conductivity. This paper represents the studies on the breakdown voltage of transformer oil filled with the various concentrations of CNT nanomaterials at various gap distances considering the effect of dispersant and the potential mechanisms. This experimental setup was done according to IEC 60156 standards [8].

\section{EXPERIMENTAL}

\subsection{Preparation of CNT Nanofluids}

The based mineral oil has been supplied by Hyrax Oil Sdn. Bhd., while CNT properties were described in Table 1.

Table 1. The properties of carbon nanotubes

\begin{tabular}{cc}
\hline Parameter & Value \\
\hline Outer Diameter & $<8 \mathrm{~nm}$ \\
Inner Diameter & $2-5 \mathrm{~nm}$ \\
Length & $10-30 \mu \mathrm{m}$ \\
Purity & $95 \%$ \\
\hline
\end{tabular}

The CNTs were weighed in five different concentrations $(0.01 \mathrm{~g} / \mathrm{L}, 0.03 \mathrm{~g} / \mathrm{L}, 0.05 \mathrm{~g} / \mathrm{L}, 0.1 \mathrm{~g} / \mathrm{L}$ and $0.2 \mathrm{~g} / \mathrm{L}$ ) by using an analytical balance. After weighed, the CNT nanomaterials were mixed with mineral oil. The CNT nanomaterials were dispersed through ultra-sonication equipment for one hour. In order to disperse CNT nanomaterials, the sound energy with frequency less than $25 \mathrm{kHz}$ was applied towards the CNT nanofluids/mixture. The sonication 
technique was implemented utilizing a sonicator equipment with $700 \mathrm{~W}$ power rating and the amplitude was set at $10 \%$ and the dispersion timing cycle was set to 5 seconds on; 3 seconds off intervals for duration of 60 minutes.

\subsection{AC Breakdown Voltage Test}

AC breakdown test was performed by using BAUR Automatic $50 \mathrm{~Hz}$ Electrical Breakdown Voltage Tester with proper procedures and precautions according to IEC 60156 standard. The rate of rise voltage was set at $2 \mathrm{kV} / \mathrm{s}$ and initial standing time of 2 minutes was fixed before voltage applied. The BAUR breakdown voltage analyzer consists of a test cell with $400 \mathrm{ml}$ capacity of oil samples with mushroom-mushroom shaped electrodes. The gap distance between the electrodes is possible to vary based on design and specification requirement. As for this experiment, breakdown voltages of CNT nanofluids with three different gap distances were evaluated. The CNT nanofluids samples were carefully filled into the test cell in order to avoid the air bubbles formation. There were total of 50 measurements of breakdown voltage were measured for each samples.

\section{STATISCAL ANALYSIS}

For manufacturing a transformer, a designer requires to refer the minimum withstand voltage level of the insulating oil rather than based on average breakdown voltage produce. Generally, there are two popular types of statistical analysis used to interpret the probability distribution of breakdown failure which are normal distribution and Weibull distribution [9]. Weibull distribution is more preferable due to ability to provide reasonable accurate failure analysis and failure forecasts by referring to extremely small amount of samples [10]. Therefore, Weibull distribution was used in this paper to calculate the probability of breakdown failure at certain level. There are three significant probability of distribution in breakdown voltages which have been identified in this paper, which are 1\%,50\% and $90 \%$. As for insulating material for high voltage equipment, probability failure of $1 \%$ is known as risk level while $50 \%$ of probability is the standard value in order to design transformer insulation. The high expected breakdown voltage for industry usually measured at $90 \%$ probability of breakdown voltage which analyzed based on Weibull distribution. 


\subsection{Analysis Data (1.5mm Gap Distance)}

The AC breakdown voltages patterns of CNT nanofluids at $1.5 \mathrm{~mm}$ gap distance for 50 readings were plotted in Fig. 1.
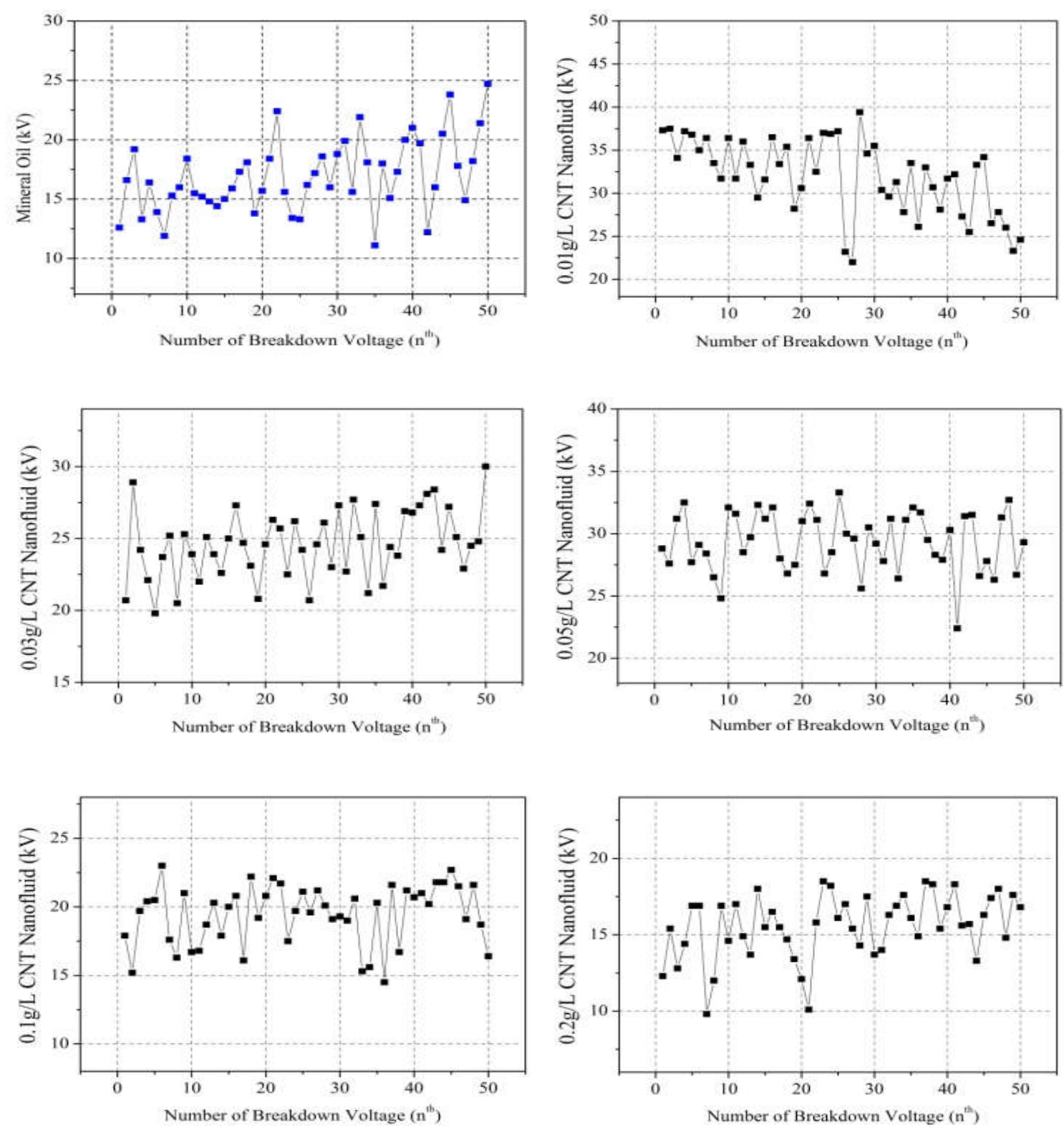

Fig.1. The AC breakdown voltages pattern for various CNTs concentration dispersed in mineral oil at $1.5 \mathrm{~mm}$ gap distance

Based on the graphs, there were no upward or downward trend exist, instead there are fluctuation observed in all range of CNT nanofluids. These prove the effectiveness of energy control of AC Breakdown Analyzer. The comparison of mean AC breakdown voltages and 
standard deviations of CNT nanofluids and mineral oil were shown in Table 2 and Fig. 2. The standard deviation values measured in all types of oil samples were quite small and considerable. Moreover, most of CNT nanofluids breakdown voltage values deviates lower than reference sample which is mineral oil. The data was considered valid due to the measurement of 50 readings of breakdown voltages were concentrated around the mean value.

Table 2. Comparison of AC voltages for $1.5 \mathrm{~mm}$ gap distance

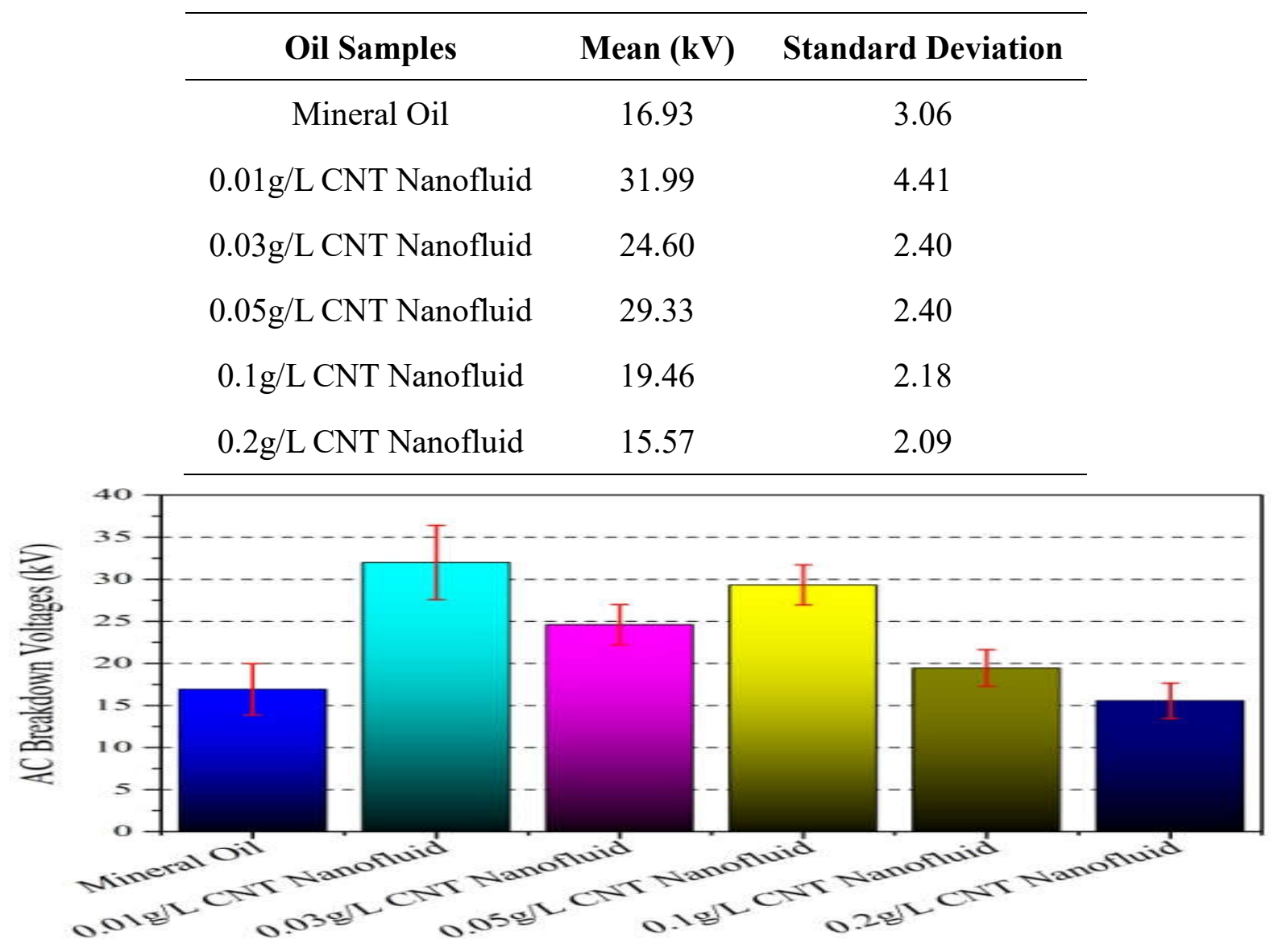

Fig.2. Mean AC breakdown voltages for mineral oil and CNT nanofluids at $1.5 \mathrm{~mm}$ gap distance

It was figure out that all types of CNT nanofluids performances were higher than mineral oil except for $0.2 \mathrm{~g} / \mathrm{L}$ of CNT's concentration. For $0.01 \mathrm{~g} / \mathrm{L}$ of CNT nanofluid, there was an improvement as much as $88.95 \%$ compared to mineral oil while $0.03 \mathrm{~g} / \mathrm{L}$ improved $45.30 \%$, $0.05 \mathrm{~g} / \mathrm{L}$ improved $73.24 \%$ and $0.1 \mathrm{~g} / \mathrm{L}$ improved $14.94 \%$ at $1.5 \mathrm{~mm}$ gap distance. However, as the amount of CNTs increased to $0.2 \mathrm{~g} / \mathrm{L}$ concentration, the average value of $\mathrm{AC}$ breakdown voltage was slightly decreased to $15.57 \mathrm{kV}$ or resembled as $-8.02 \%$ decrement compared to mineral oil sample. Fig. 3-Fig. 8 show the Weibull distribution analysis to model the AC 
breakdown voltage for mineral oil and $0.01 \mathrm{~g} / \mathrm{L}-0.2 \mathrm{~g} / \mathrm{L}$ concentration of CNT nanofluids at $1.5 \mathrm{~mm}$ gap distance.

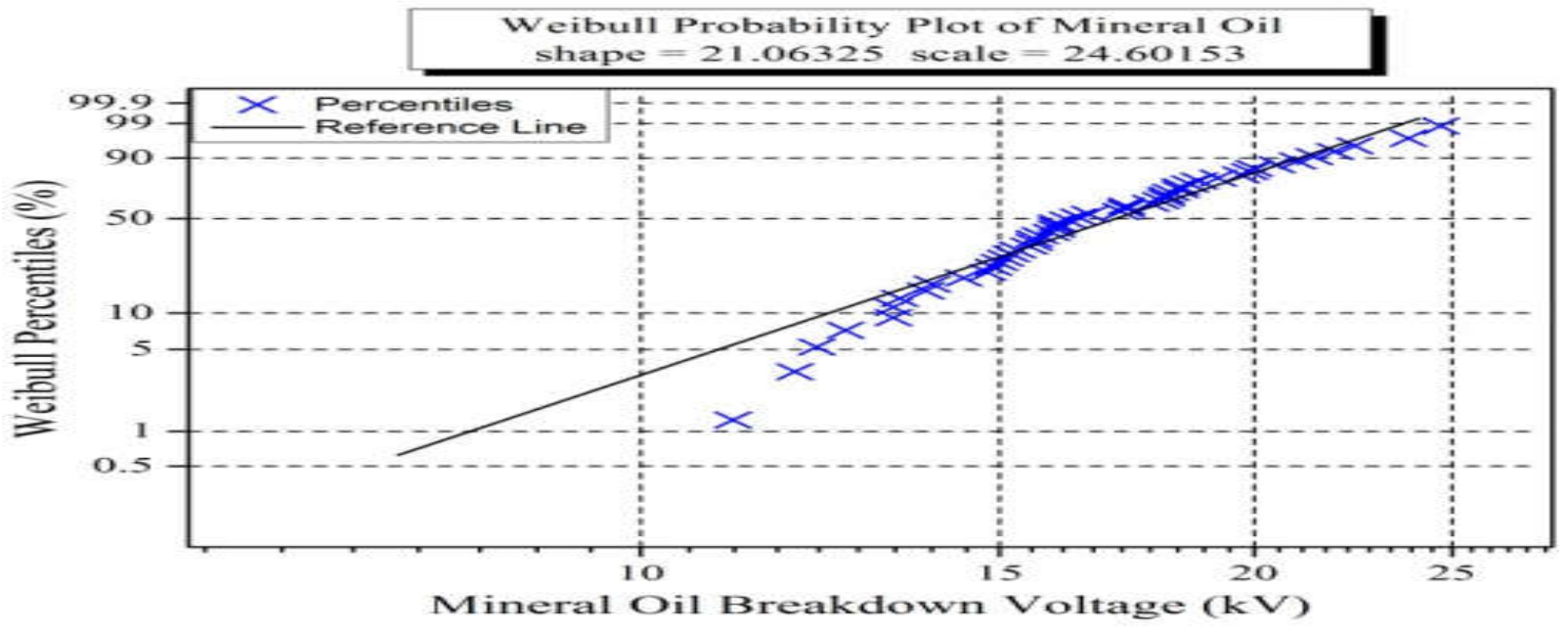

Fig.3. Weibull distributions of mineral oil at $1.5 \mathrm{~mm}$ gap distance

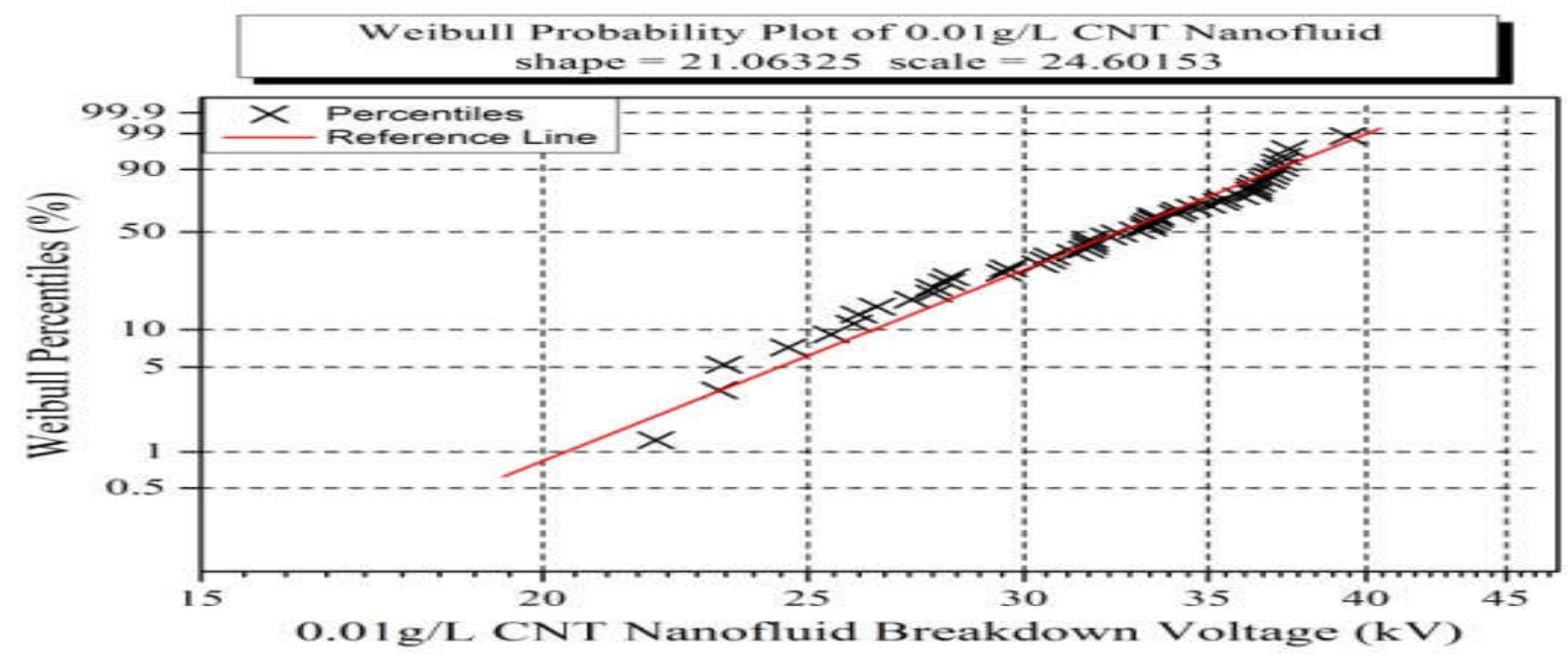

Fig.4. Weibull distributions of $0.01 \mathrm{~g} / \mathrm{L}$ CNT nanofluid at $1.5 \mathrm{~mm}$ gap distance

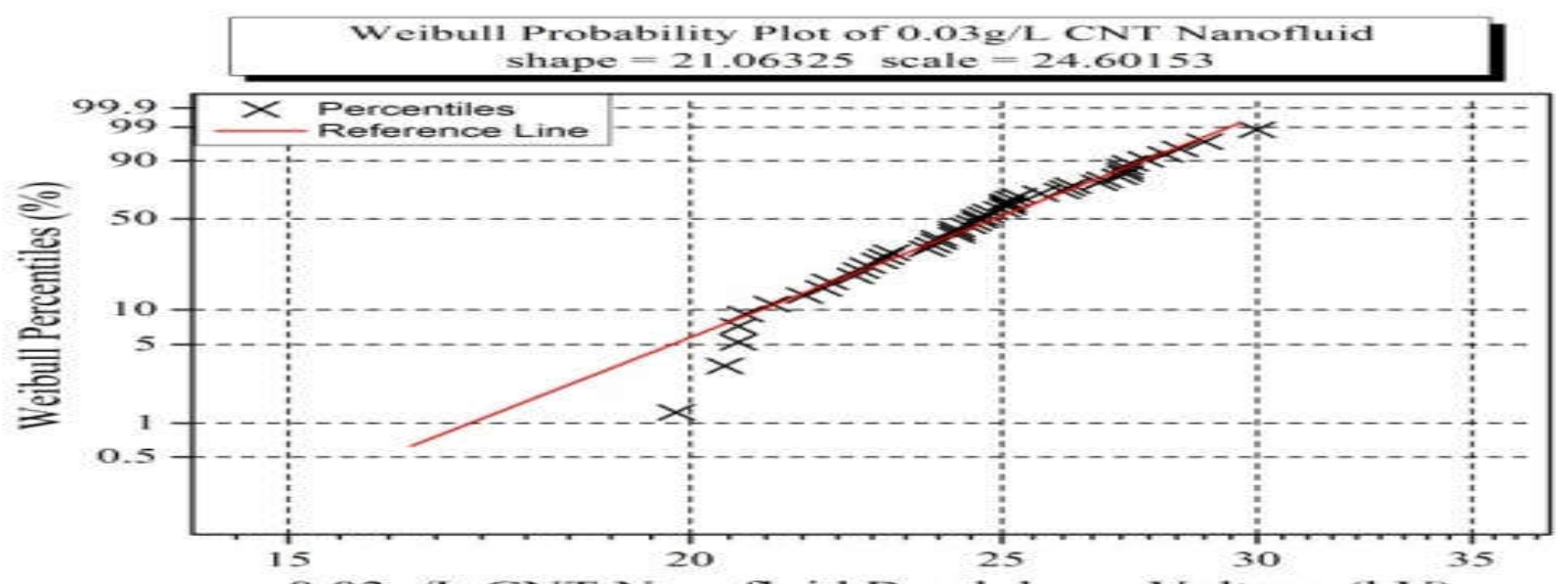

$0.03 \mathrm{~g} / \mathrm{L}$ CNT Nanofluid Breakdown Voltage (kV)

Fig.5. Weibull distributions of $0.03 \mathrm{~g} / \mathrm{L} \mathrm{CNT}$ nanofluid at $1.5 \mathrm{~mm}$ gap distance 


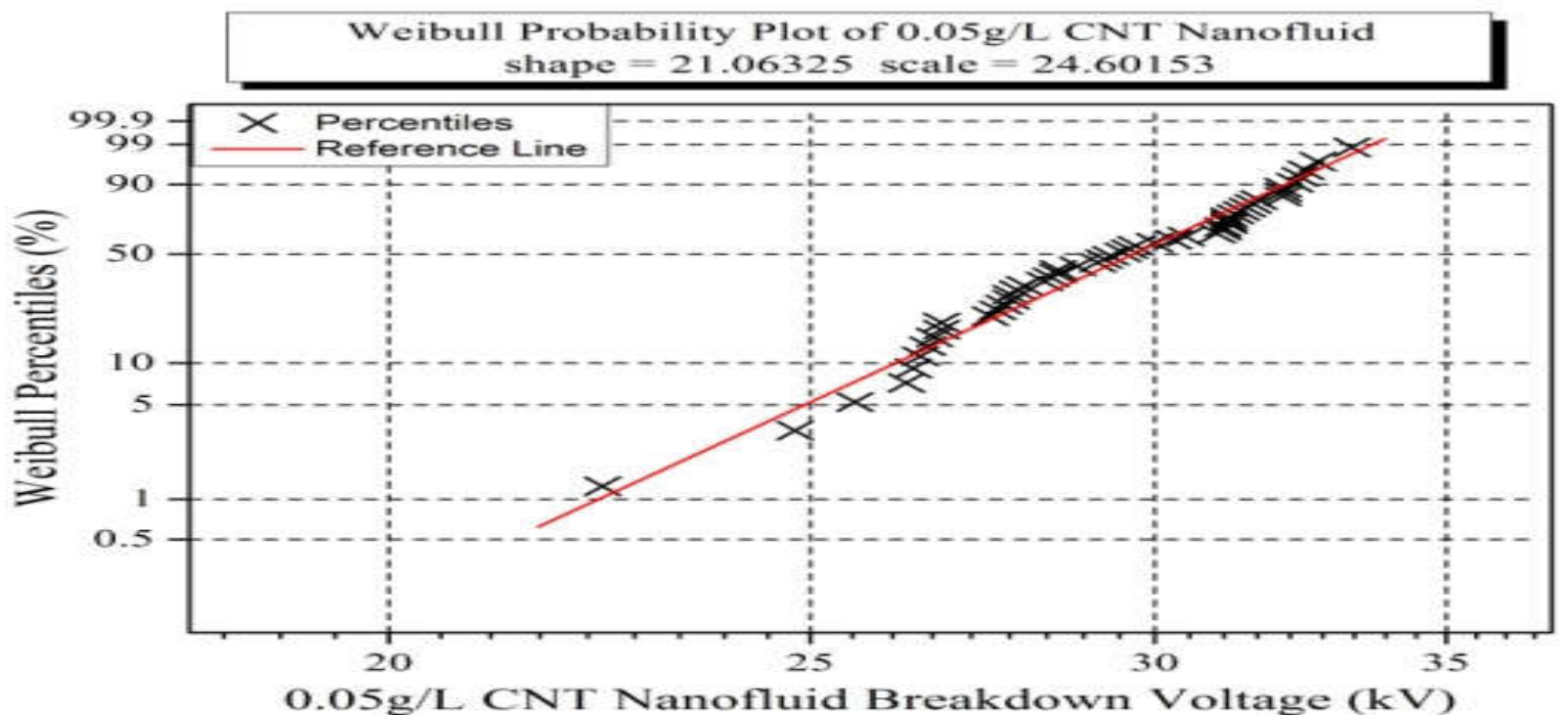

Fig.6. Weibull distributions of $0.05 \mathrm{~g} / \mathrm{L}$ CNT Nanofluid at $1.5 \mathrm{~mm}$ gap distance

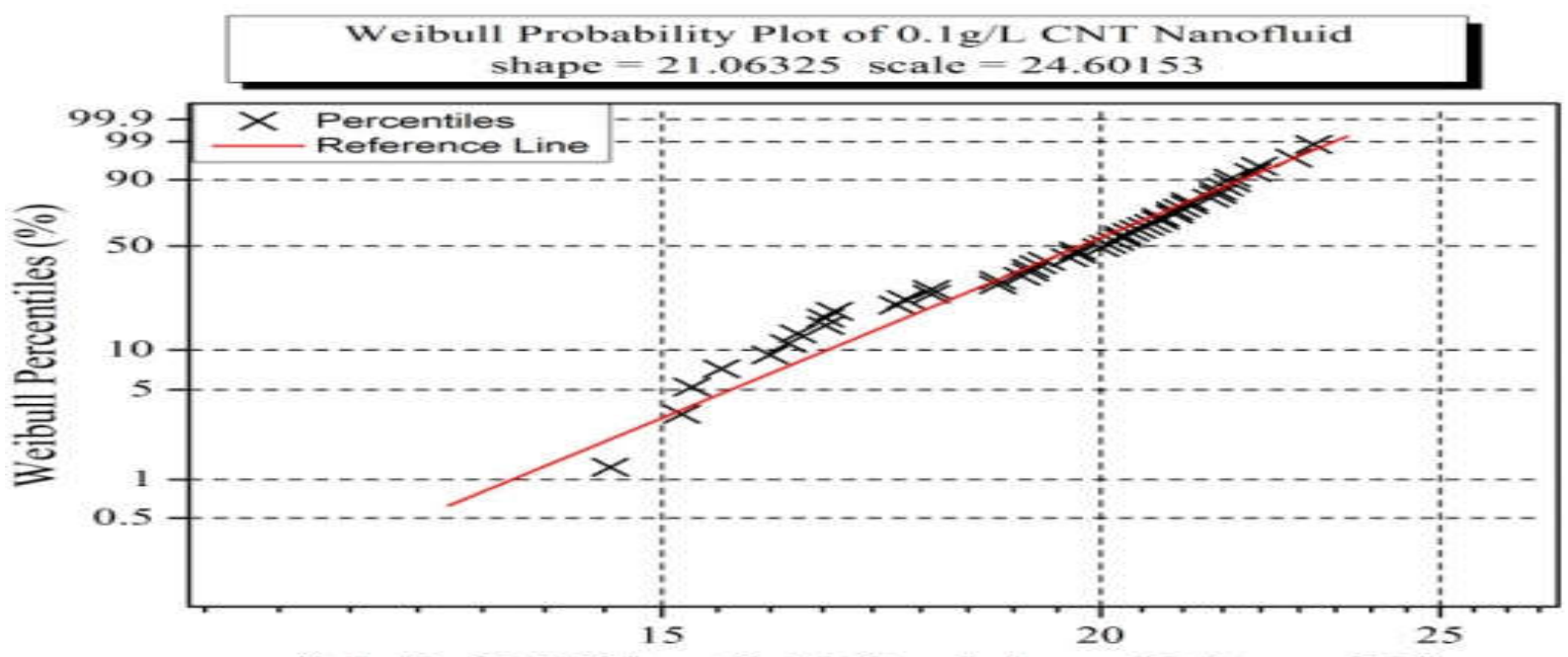

0.1 $\mathrm{g} / \mathrm{L}$ CNT Nanofluid Breakdown Voltage (kV)

Fig.7. Weibull distributions of $0.1 \mathrm{~g} / \mathrm{L} \mathrm{CNT} \mathrm{Nanofluid} \mathrm{at} 1.5 \mathrm{~mm}$ gap distance

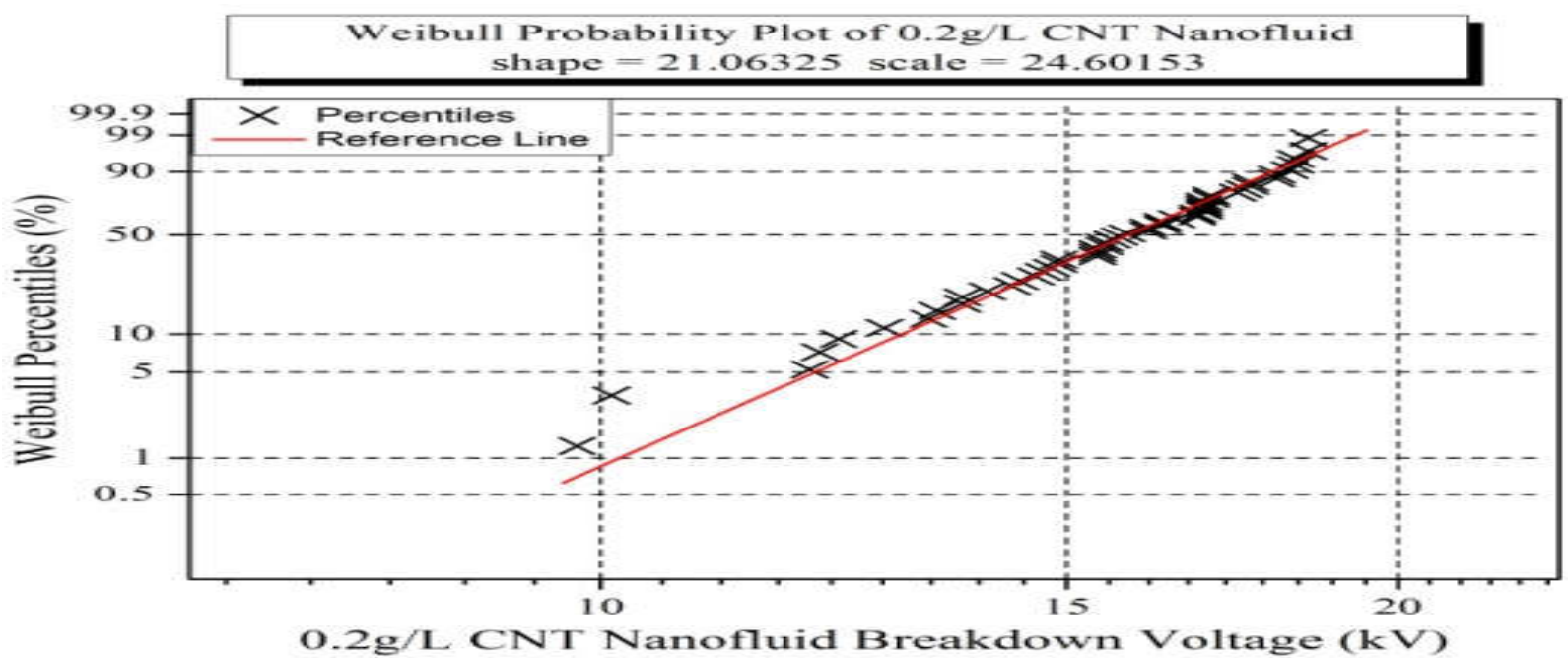

Fig.8. Weibull distributions of $0.2 \mathrm{~g} / \mathrm{L}$ CNT Nanofluid at $1.5 \mathrm{~mm}$ gap distance 
Table 3 shows the probability of breakdown failure at $1 \%, 50 \%$ and $90 \%$. At $1 \%$ breakdown probability, CNT nanofluid achieved an increase of 1.71 times compare to mineral oil. As for $50 \%$ normal breakdown failure probability which fit for designing transformer gain 1.90 times increment while for $90 \%$ probability of breakdown voltage achieved 1.76 increments. For early stage of investigation at $1.5 \mathrm{~mm}$ gap distance, it can be seen that CNT nanomaterials could possibly influenced the breakdown voltage performance of based mineral oil. For further investigation and verification, the same methods have been applied but with two different gap distances.

Table 3. Probability of AC breakdown voltages (1.5mm gap distance)

\begin{tabular}{cccc}
\hline Oil Samples & P1 (\%) & P50 (\%) & P90 (\%) \\
\hline Mineral Oil & 8.24 & 17.11 & 21.04 \\
$0.01 \mathrm{~g} / \mathrm{L}$ CNT Nanofluid & 20.40 & 32.50 & 37.10 \\
$0.03 \mathrm{~g} / \mathrm{L}$ CNT Nanofluid & 17.06 & 24.86 & 27.66 \\
$0.05 \mathrm{~g} /$ L CNT Nanofluid & 22.35 & 29.66 & 32.14 \\
$0.1 \mathrm{~g} / \mathrm{L}$ CNT Nanofluid & 13.60 & 19.74 & 21.94 \\
$0.2 \mathrm{~g} / \mathrm{L} \mathrm{CNT} \mathrm{Nanofluid}$ & 10.17 & 15.81 & 17.93 \\
\hline
\end{tabular}

\subsection{Analysis Data (2.5mm Gap Distance)}

The scattered diagram of AC breakdown voltage for 50 readings of breakdown voltages of mineral oil and CNT nanofluids at $2.5 \mathrm{~mm}$ gap distance were tabulated in Fig. 9. Referring to the graphs, the distributions of data seem fluctuated for all types of oils samples. Thus, all the data is considered as acceptable and valid to be analyzed further.
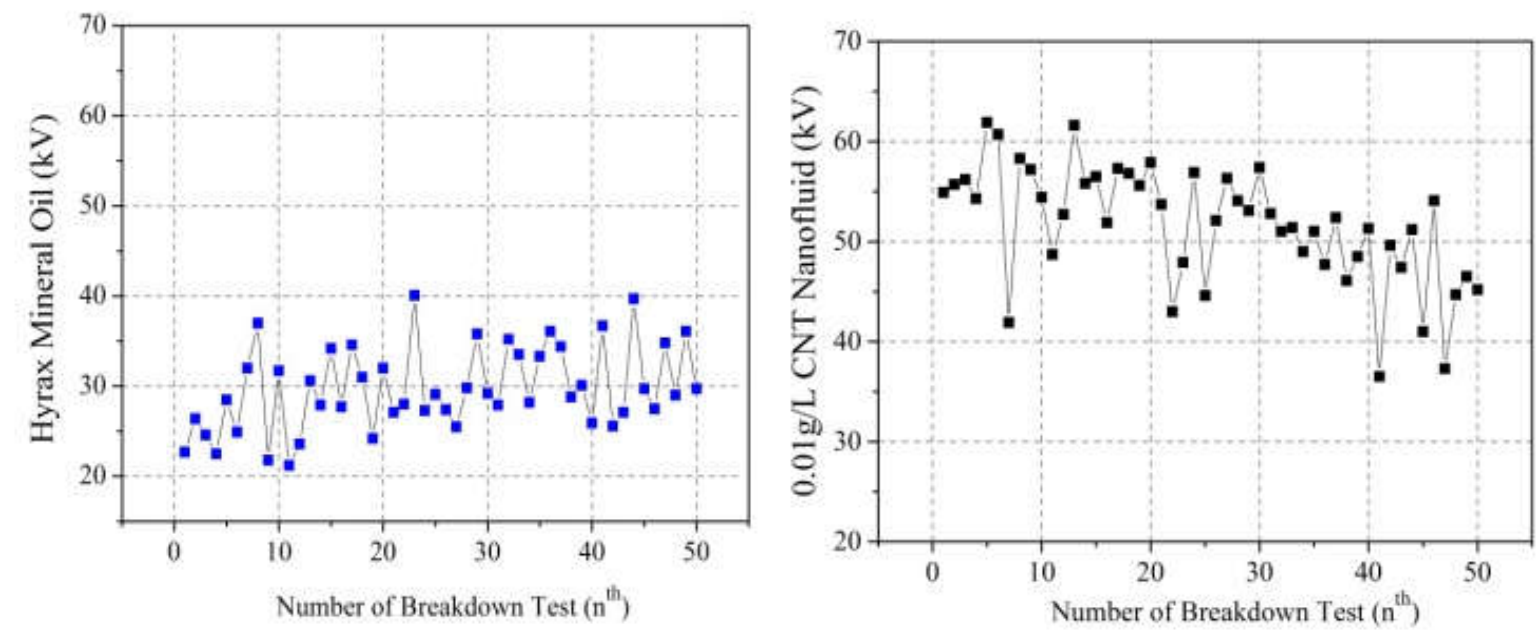

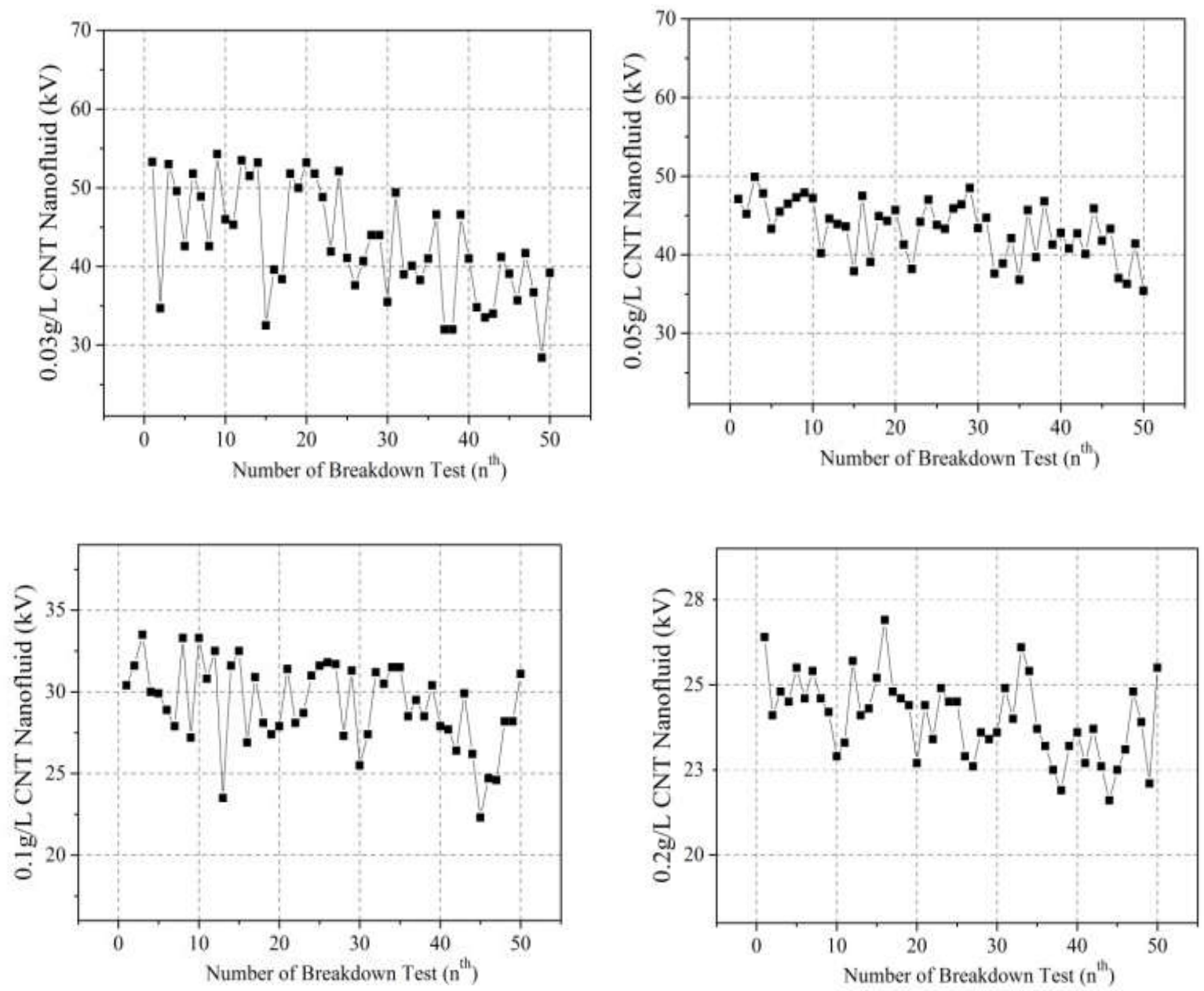

Fig.9. The AC breakdown voltages pattern for various CNTs concentration dispersed in mineral oil at $2.5 \mathrm{~mm}$ gap distance

Table 4. Comparison of AC breakdown voltages for $2.5 \mathrm{~mm}$ gap distance

\begin{tabular}{ccc}
\hline Oil Samples & Mean $(\mathbf{k V})$ & Standard Deviation \\
\hline Mineral Oil & 29.75 & 4.64 \\
$0.01 \mathrm{~g} / \mathrm{L}$ CNT Nanofluid & 51.68 & 5.85 \\
$0.03 \mathrm{~g} / \mathrm{L}$ CNT Nanofluid & 43.07 & 7.10 \\
$0.05 \mathrm{~g} / \mathrm{L}$ CNT Nanofluid & 38.46 & 5.43 \\
$0.1 \mathrm{~g} / \mathrm{L}$ CNT Nanofluid & 29.25 & 2.60 \\
$0.2 \mathrm{~g} / \mathrm{L}$ CNT Nanofluid & 24.04 & 1.19 \\
\hline
\end{tabular}

The standard deviations produced were small and it can be considered that the data were very close to the average value. A high standard deviation means that the data was spread out and unacceptable. 


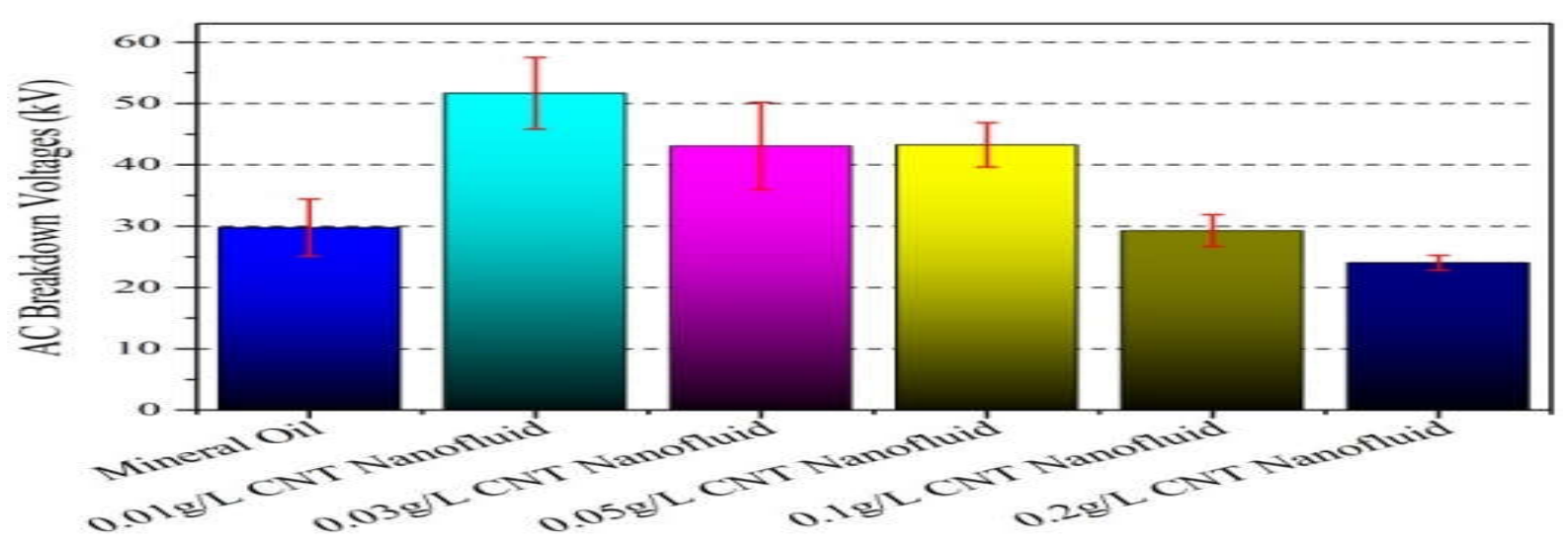

Fig.10. Mean AC breakdown voltages for mineral oil and CNT nanofluids at $2.5 \mathrm{~mm}$ gap distance

Fig. 10 shows the comparison of mean AC breakdown voltages between mineral oil and five concentrations of CNT nanofluids. It can be observed that $0.01 \mathrm{~g} / \mathrm{L}$ CNT nanofluid having the highest mean breakdown voltage, which is $51.68 \mathrm{kV}$ ( $73.70 \%$ improvement) compared to other oil samples. Results for $0.03 \mathrm{~g} / \mathrm{L}$ and $0.05 \mathrm{~g} / \mathrm{L}$ CNT nanofluids performances also achieved good results compared to the reference mineral oil breakdown voltage. These proved CNT nanofluids could possibly improve reliability of transformer oil in future. However, different results were achieved for $0.1 \mathrm{~g} / \mathrm{L}$ and $0.2 \mathrm{~g} / \mathrm{L}$ CNT nanofluids. There were $-1.68 \%$ and $-19.22 \%$ decrements of breakdown performances compared to reference mineral oil. This occurrence might be due to the agglomeration of CNTs in the based mineral oil which causes performance to drop. Thus, in order to investigate more detailed, observation of pattern and behaviour of 50 readings of mineral oil and CNT nanofluids electrical breakdown at $2.5 \mathrm{~mm}$ gap distance has been model by using Weibull distribution analysis as shown in Fig. 11-Fig. 16.

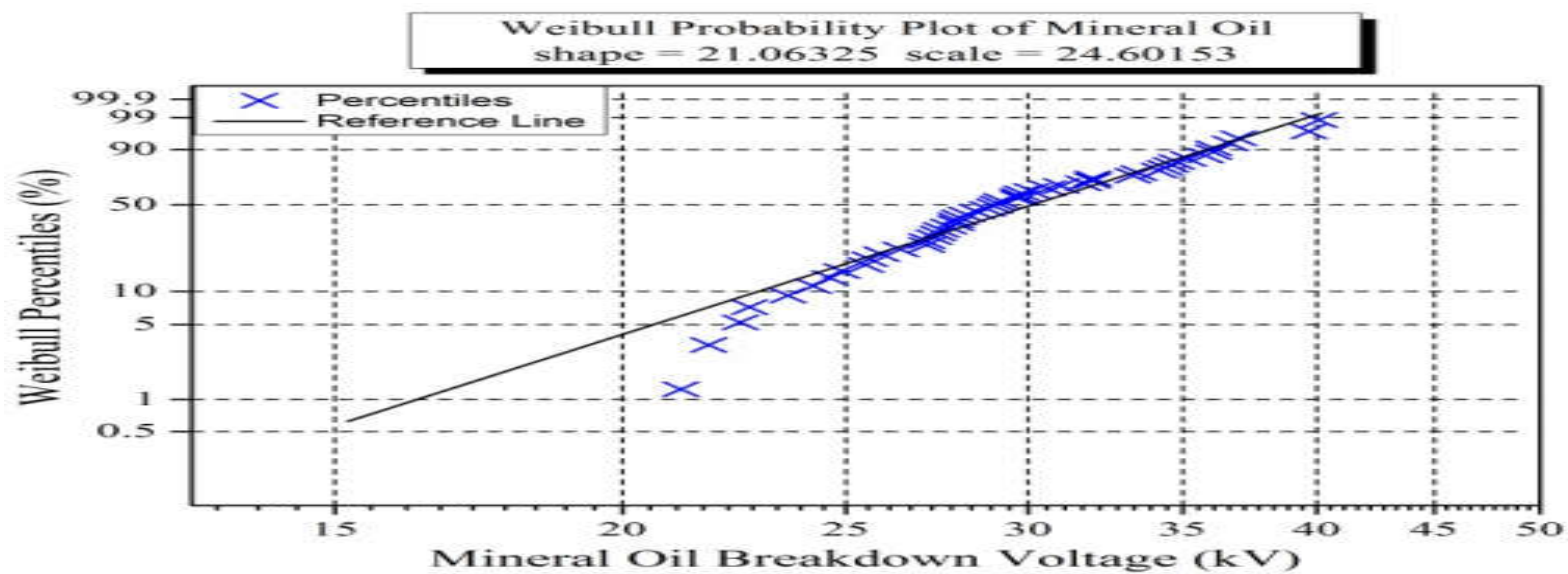

Fig.11. Weibull distributions of mineral oil at $2.5 \mathrm{~mm}$ gap distance 


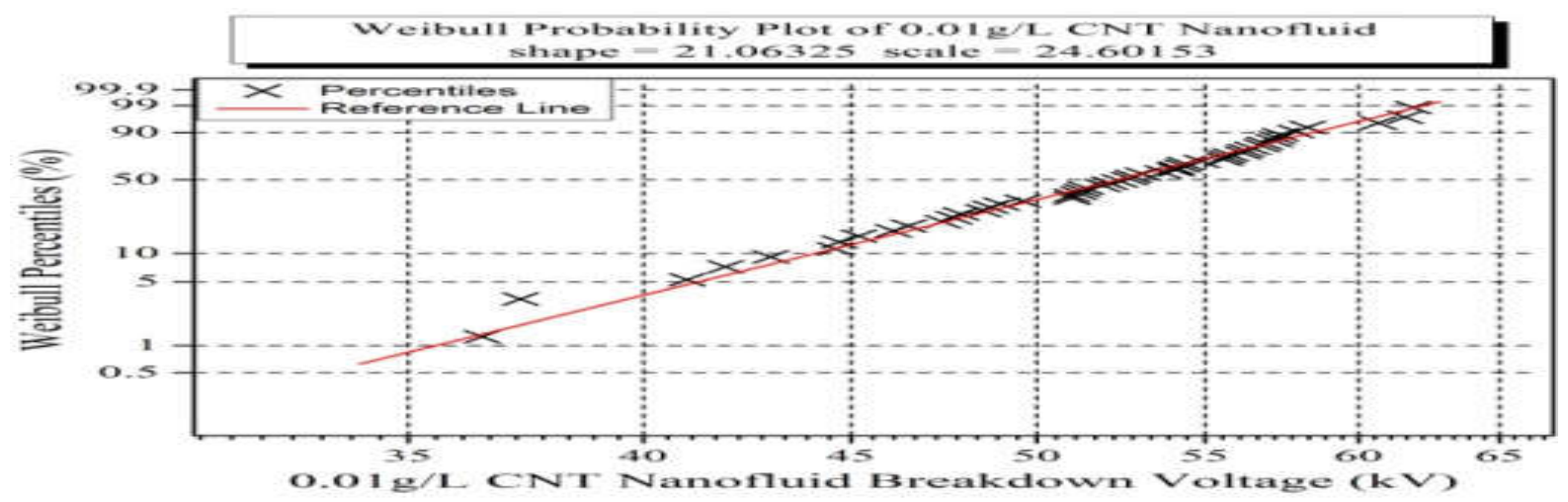

Fig.12. Weibull distributions of $0.01 \mathrm{~g} / \mathrm{L} \mathrm{CNT}$ nanofluid at $2.5 \mathrm{~mm}$ gap distance

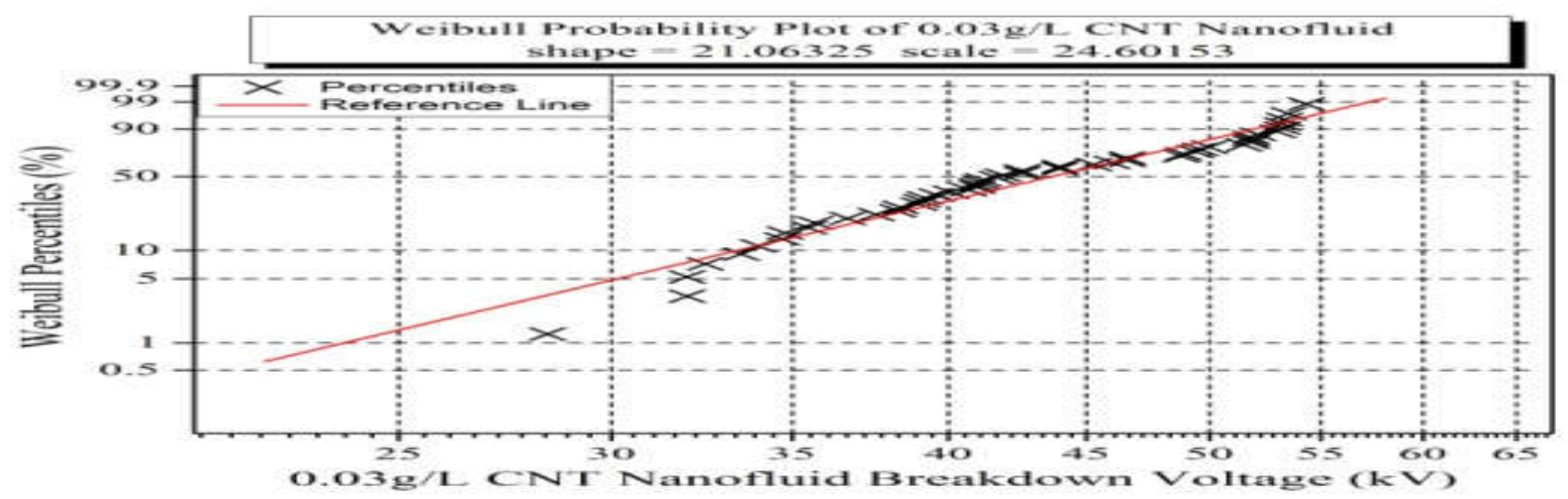

Fig.13. Weibull distributions of $0.03 \mathrm{~g} / \mathrm{L}$ CNT nanofluid at $2.5 \mathrm{~mm}$ gap distance

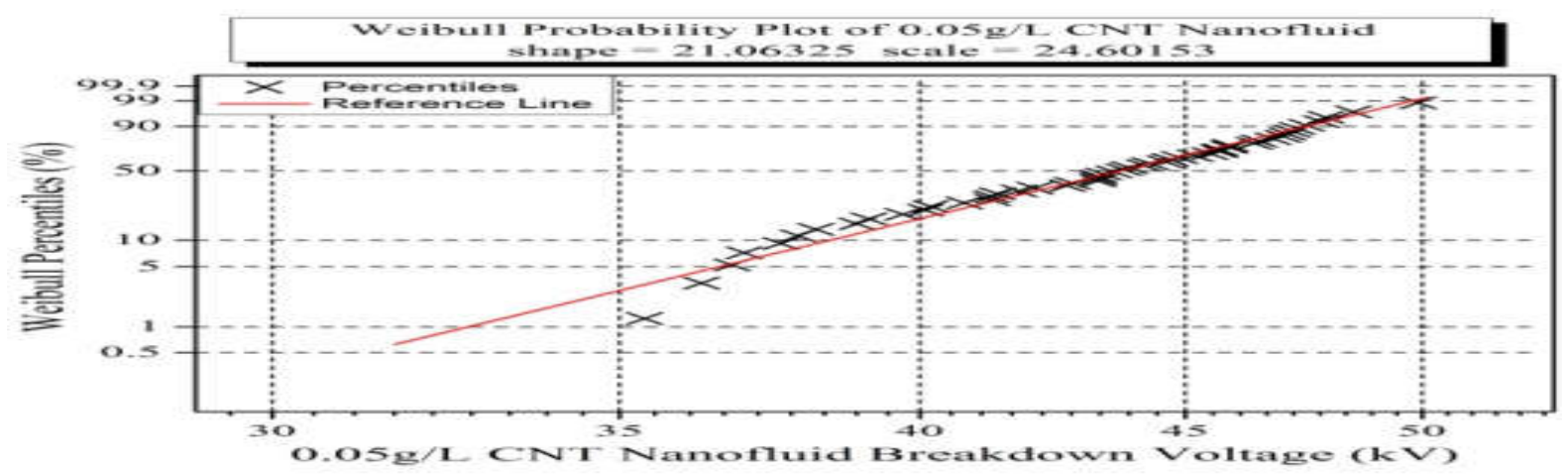

Fig.14. Weibull distributions of $0.05 \mathrm{~g} / \mathrm{L}$ CNT nanofluid at $2.5 \mathrm{~mm}$ gap distance

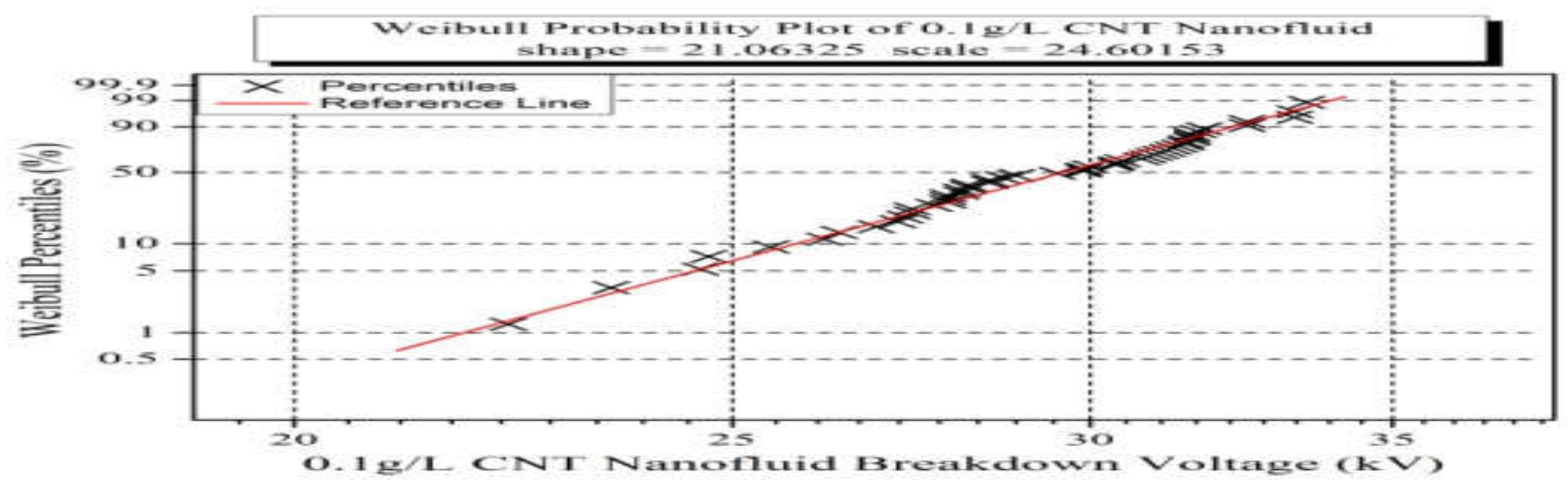

Fig. 15. Weibull distributions of $0.1 \mathrm{~g} / \mathrm{L} \mathrm{CNT}$ nanofluid at $2.5 \mathrm{~mm}$ gap distance. 


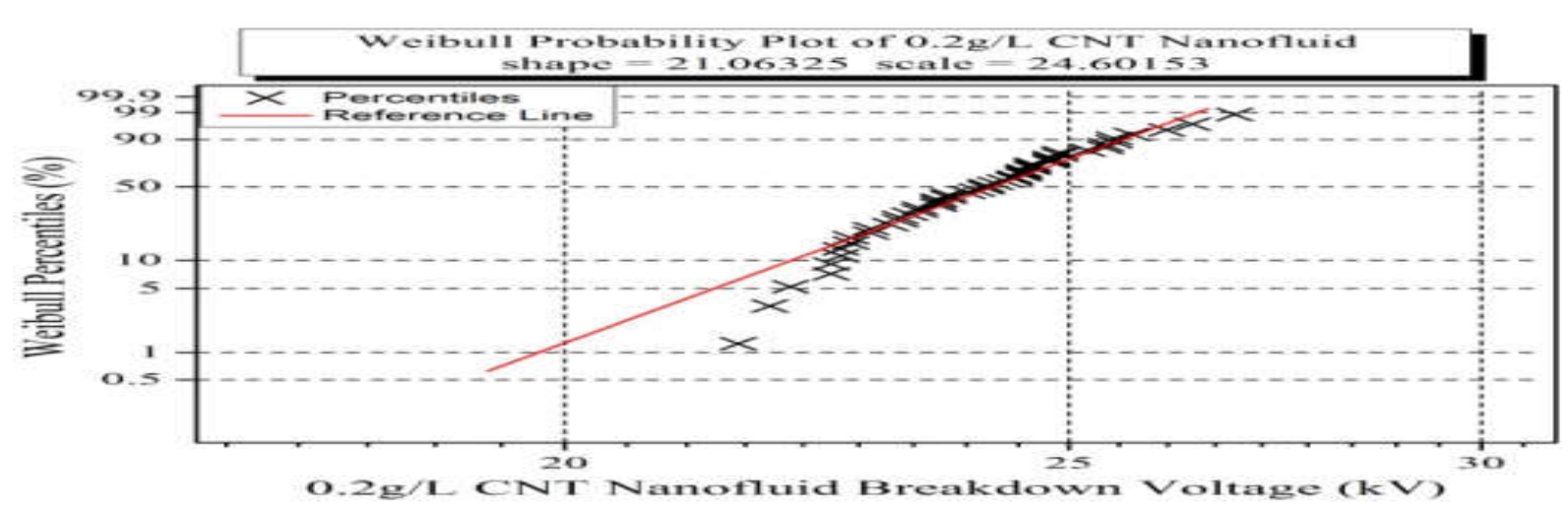

Fig.16. Weibull distributions of $0.2 \mathrm{~g} / \mathrm{L}$ CNT nanofluid at $2.5 \mathrm{~mm}$ gap distance

Table 5. Probability of AC breakdown voltages ( $2.5 \mathrm{~mm}$ gap distance)

\begin{tabular}{cccc}
\hline Oil Samples & P1 (\%) & P50 (\%) & P90 (\%) \\
\hline Mineral Oil & 16.29 & 30.09 & 35.85 \\
$0.01 \mathrm{~g} /$ L CNT Nanofluid & 35.58 & 52.38 & 58.44 \\
$0.03 \mathrm{~g} /$ L CNT Nanofluid & 23.88 & 43.73 & 51.90 \\
$0.05 \mathrm{~g} /$ L CNT Nanofluid & 23.62 & 39.03 & 45.00 \\
$0.1 \mathrm{~g} /$ L CNT Nanofluid & 21.80 & 29.60 & 32.27 \\
$0.2 \mathrm{~g} /$ L CNT Nanofluid & 19.78 & 24.18 & 25.60 \\
\hline
\end{tabular}

The probability of $1 \%$ withstands voltages provide significant value in designing transformer. Based on Fig. 12 and Table 5, 0.01g/L CNT nanofluid provides good linearity in Weibull plots and produce the highest breakdown voltage value among the oil samples. There was $118.42 \%$ increment achieved compared to typical transformer mineral oil used in this experiment. Instead, in $50 \%$ probability and $90 \%$ probability of breakdown voltage, there were 1.74 and 1.63 times increments were achieved. Thus, it can be seen that CNT nanomaterials were constantly getting higher results compared to mineral oil. Previously, at $1.5 \mathrm{~mm}$ gap distance, $0.1 \mathrm{~g} / \mathrm{L}$ and $0.2 \mathrm{~g} / \mathrm{L} \mathrm{CNT}$ nanofluids probability of breakdown failure having slightly decreased compare to mineral oil. However, at $2.5 \mathrm{~mm}$ gap distance, all types of CNT nanofluids unexpectedly achieved probability of breakdown voltages more than the standard mineral oil.

\subsection{Analysis Data (3.5mm Gap Distance)}

The tabulation of 50 readings of AC breakdown voltages was plotted in scatter graph as shown in Fig. 17. The breakdown voltages data plotted were level-off with the increasing test 
number, thus the measurements were considered valid and acceptable for mineral oil, $0.01 \mathrm{~g} / \mathrm{L}$, $0.03 \mathrm{~g} / \mathrm{L}, 0.05 \mathrm{~g} / \mathrm{L}, 0.1 \mathrm{~g} / \mathrm{L}$ and $0.2 \mathrm{~g} / \mathrm{L}$ CNT nanofluids.
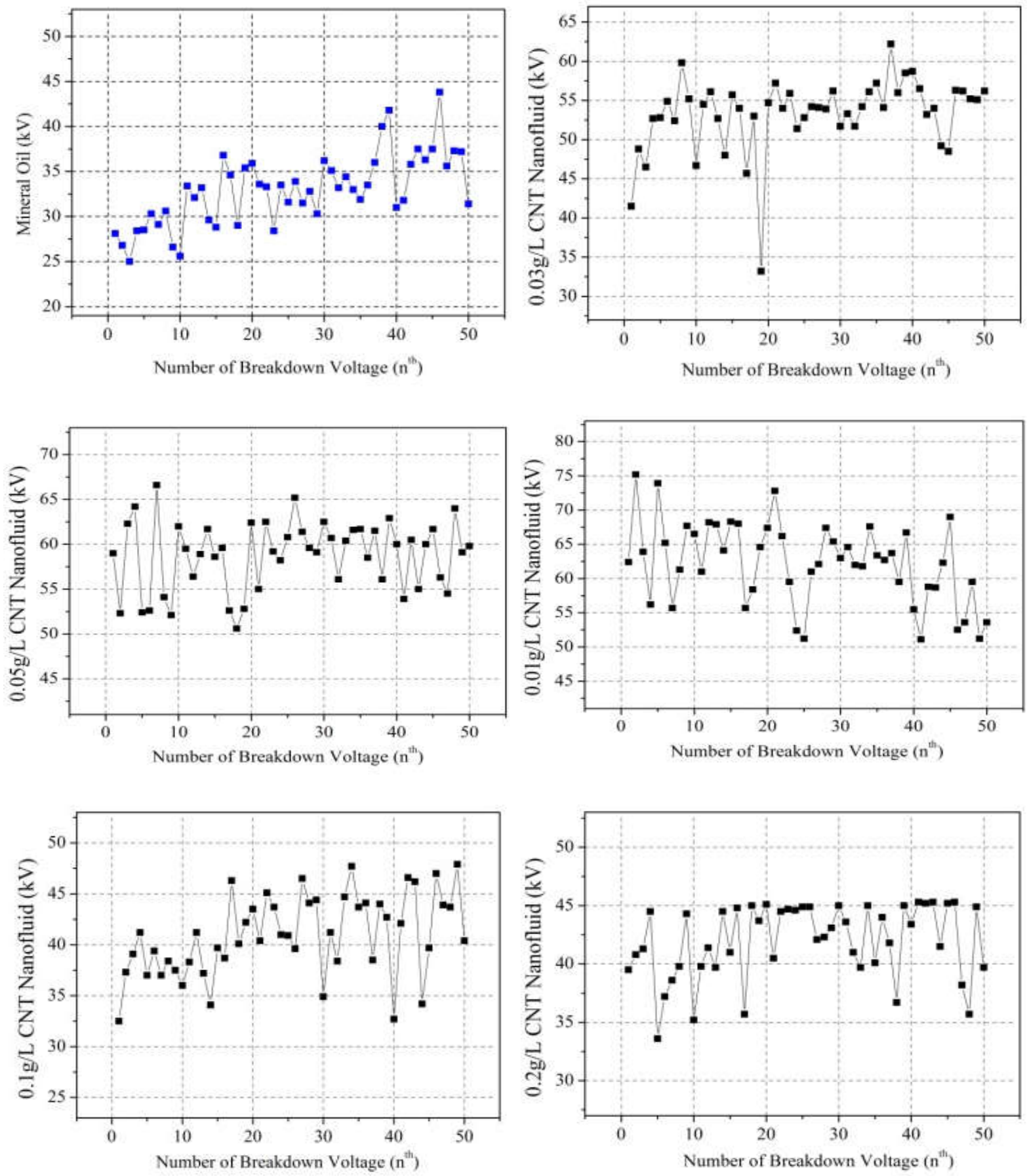

Fig.17. The AC breakdown voltages pattern for various CNTs concentration dispersed in mineral oil at $1.5 \mathrm{~mm}$ gap distance

Table 6 compute the average and standard deviation achieved from breakdown voltages measurements for mineral oil and five different concentrations of CNT nanofluids. While, Fig. 18 plot the data according to Table 6 . 
Table 6. Probability of AC breakdown voltages (3.5 $\mathrm{mm}$ gap distance)

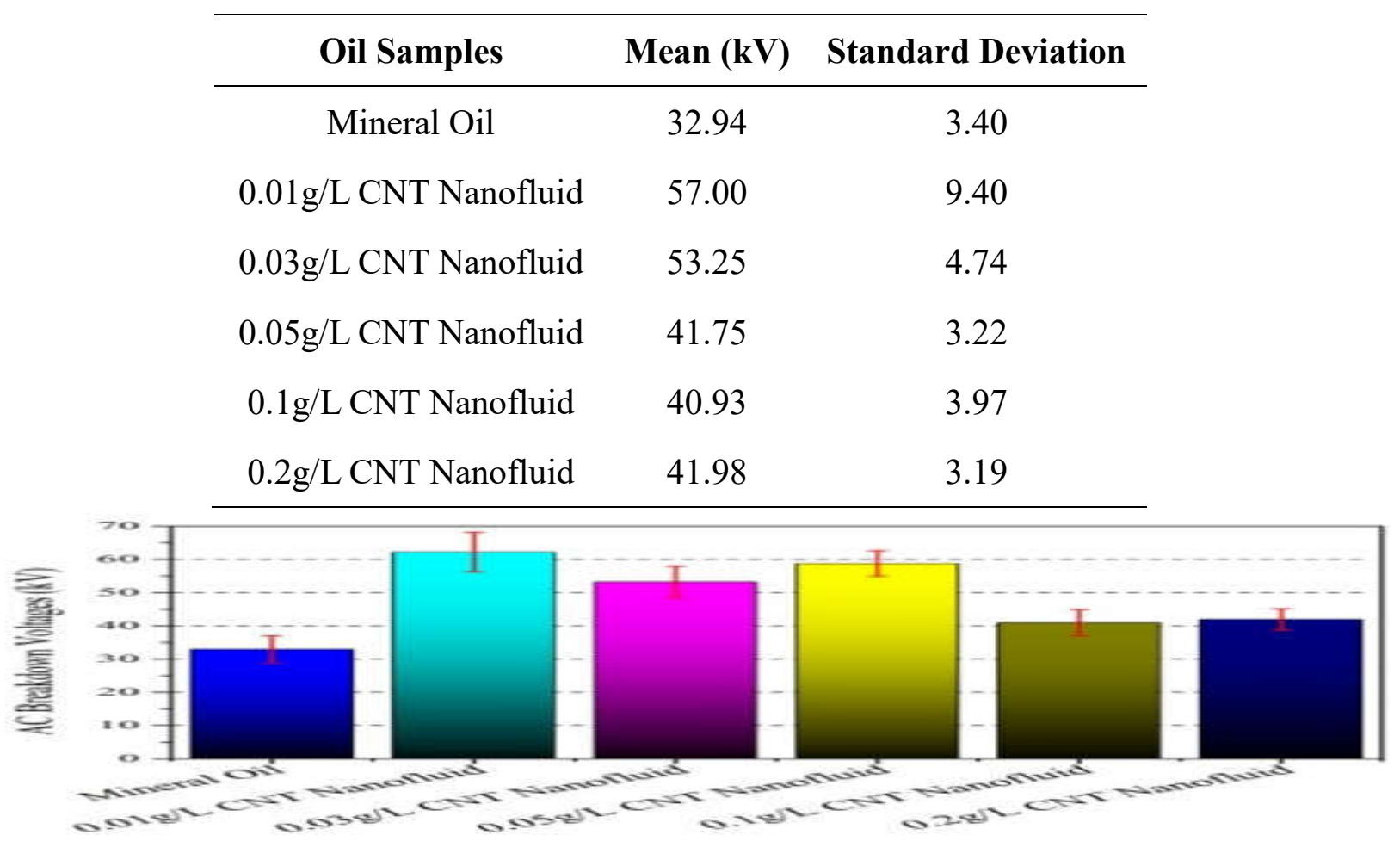

Fig.18. Mean AC breakdown voltages for mineral oil and CNT nanofluids at 3.5mm gap distance

The average breakdown voltages for CNT nanofluids were higher than standard mineral oil with 24.06 differences. The highest improvement was achieved by $0.01 \mathrm{~g} / \mathrm{L}$ CNT nanofluid with $73.02 \%$ increment while the lowest improvement was achieved by $0.1 \mathrm{~g} / \mathrm{L}$ CNT nanofluids with $24.27 \%$ increment. Hence, it can be considered that CNT nanomaterials were possible to enhance the breakdown voltage for transformer oil application more than standard industry transformer oil. The Weibull analysis results of 50 breakdown failures for mineral oil and various concentrations of CNT nanofluids are shown in Fig. 19-Fig. 24.

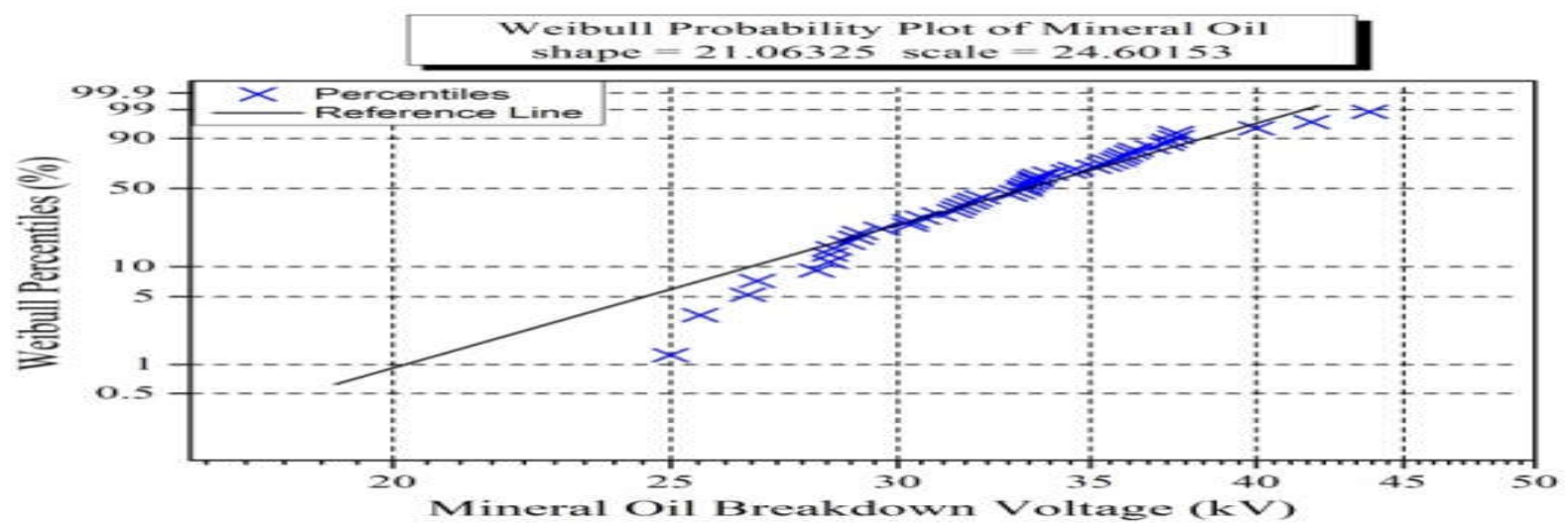

Fig.19. Weibull distributions of mineral oil at $3.5 \mathrm{~mm}$ gap distance 


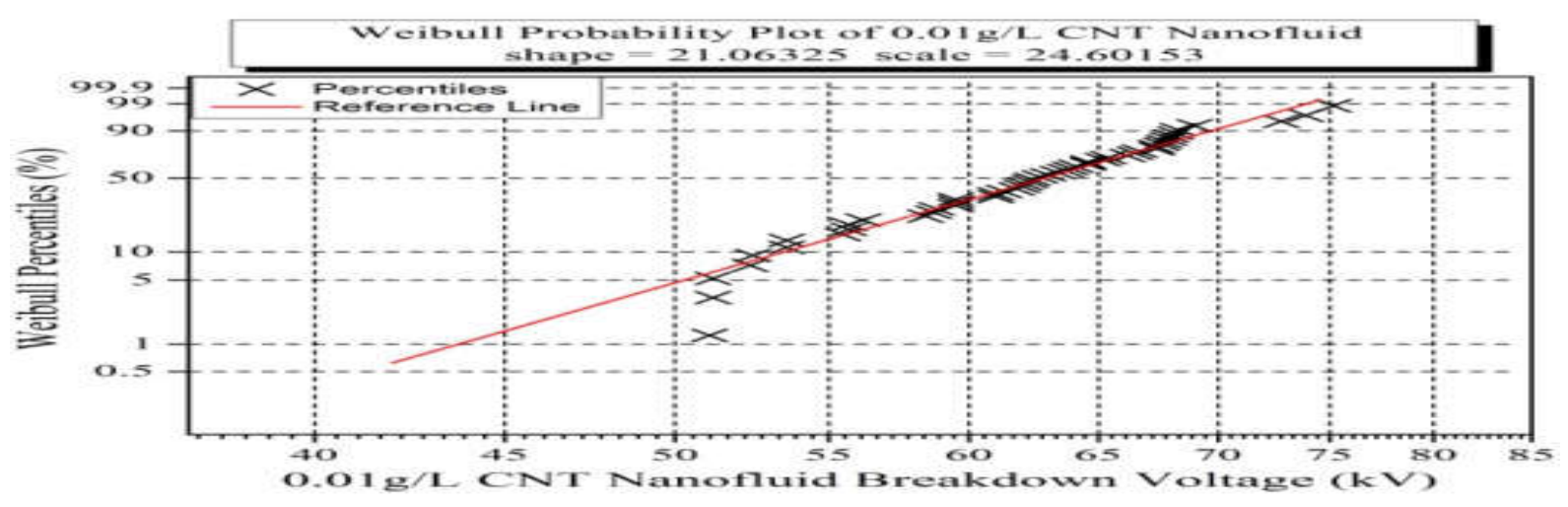

Fig.20. Weibull distributions of $0.01 \mathrm{~g} / \mathrm{L} \mathrm{CNT}$ nanofluid at $3.5 \mathrm{~mm}$ gap distance

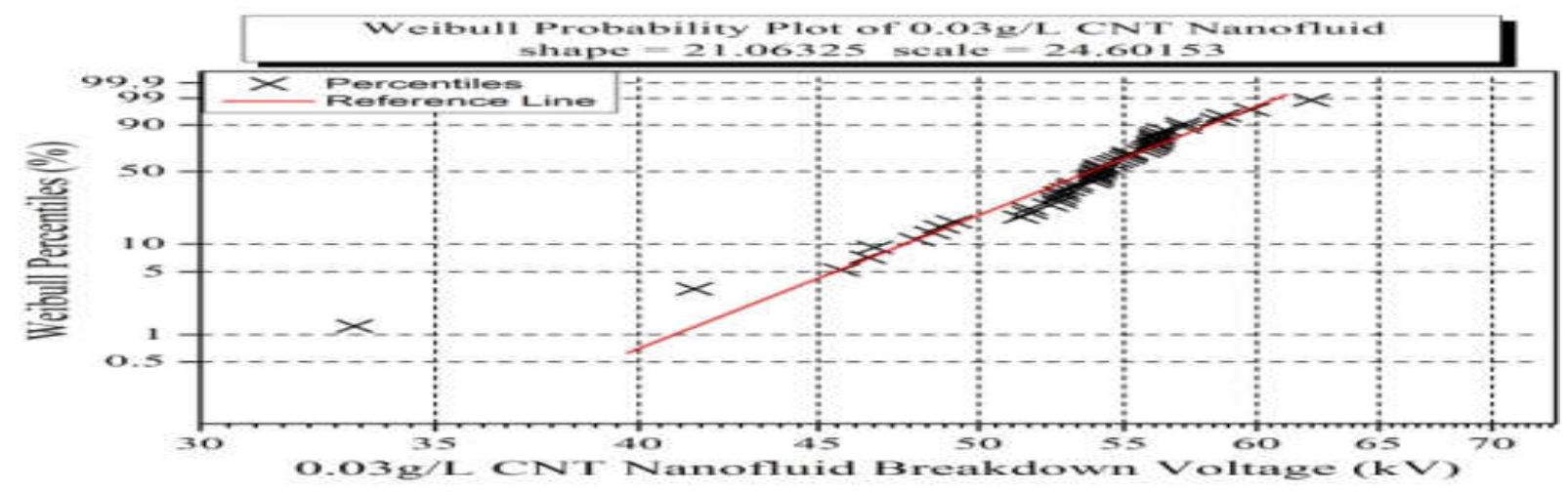

Fig.21. Weibull distributions of $0.03 \mathrm{~g} / \mathrm{L} \mathrm{CNT}$ nanofluid at $3.5 \mathrm{~mm}$ gap distance

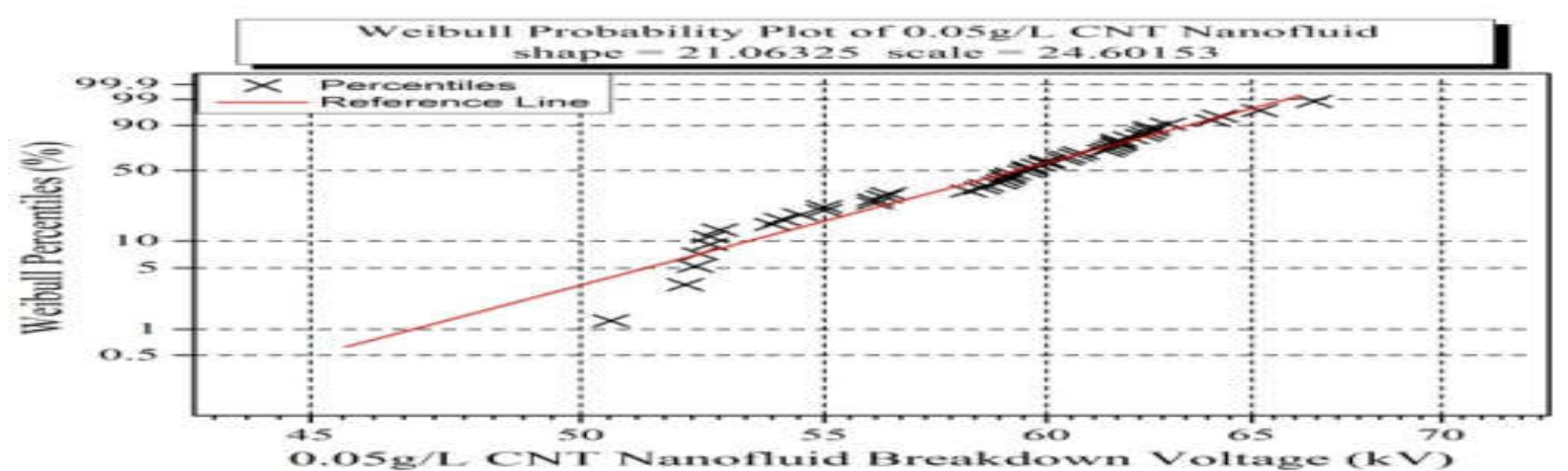

Fig.22. Weibull distributions of $0.05 \mathrm{~g} / \mathrm{L}$ CNT nanofluid at $3.5 \mathrm{~mm}$ gap distance

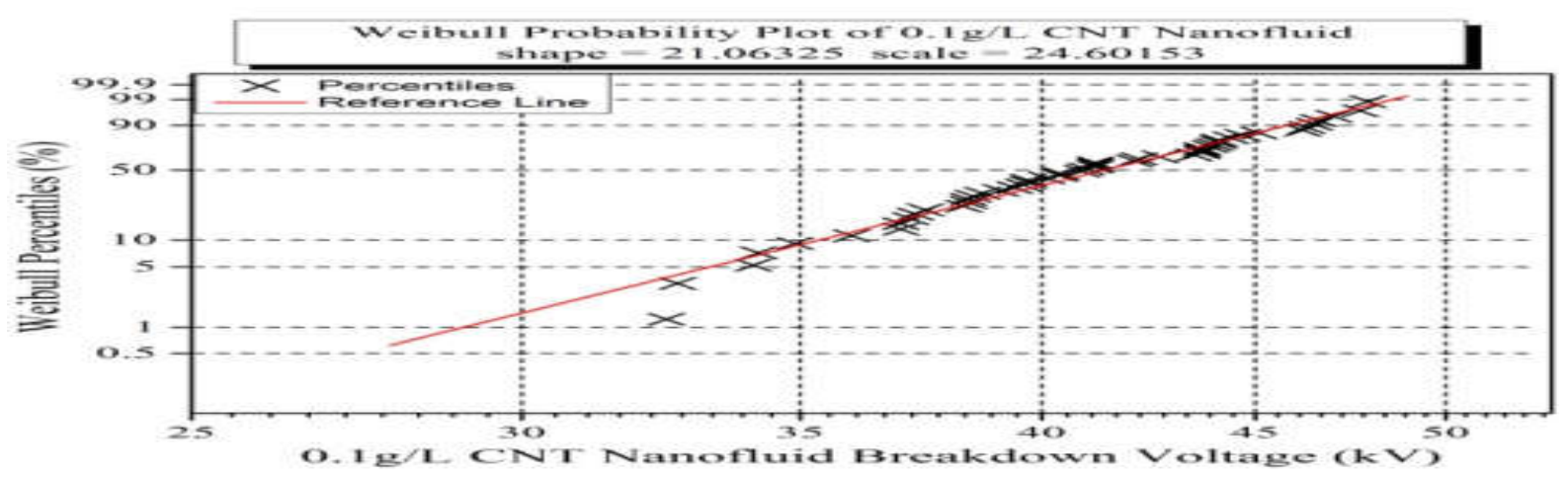

Fig.23. Weibull distributions of $0.1 \mathrm{~g} / \mathrm{L}$ CNT nanofluid at $3.5 \mathrm{~mm}$ gap distance 


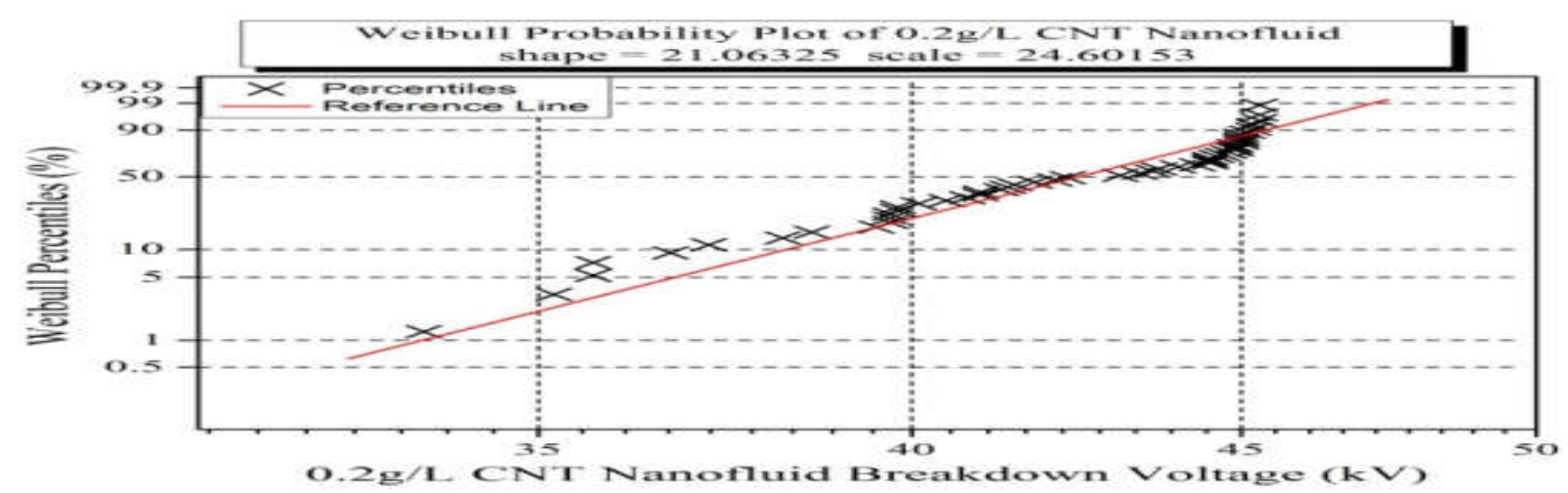

Fig.24. Weibull distributions of $0.2 \mathrm{~g} / \mathrm{L} \mathrm{CNT}$ nanofluid at $3.5 \mathrm{~mm}$ gap distance.

Table 7. Probability of AC breakdown voltages (3.5 mm gap distance)

\begin{tabular}{cccc}
\hline Oil Samples & P1 (\%) & P50 (\%) & P90 (\%) \\
\hline Mineral Oil & 20.21 & 33.26 & 38.30 \\
$0.01 \mathrm{~g} / \mathrm{L} \mathrm{CNT} \mathrm{Nanofluid}$ & 31.93 & 57.84 & 68.45 \\
$0.03 \mathrm{~g} / \mathrm{L}$ CNT Nanofluid & 40.95 & 53.82 & 58.16 \\
$0.05 \mathrm{~g} / \mathrm{L}$ CNT Nanofluid & 31.60 & 42.14 & 45.72 \\
$0.1 \mathrm{~g} / \mathrm{L}$ CNT Nanofluid & 29.04 & 41.43 & 45.80 \\
$0.2 \mathrm{~g} / \mathrm{L}$ CNT Nanofluid & 33.58 & 42.47 & 45.40 \\
\hline
\end{tabular}

Looking into the modelling Weibull results, the withstand voltage at low breakdown probability (1\%), achieved an increase of 1.03 times than mineral oil. As for standard probability (50\%) and high breakdown probability (90\%) achieves increase of 2.74 and 1.79 times compared to Hyrax mineral oil. Based on the experimental analysis from three different gap distances, it reveals that the presence of CNT nanomaterials could enhance the breakdown strength of transformer oil. However, as the amount of CNTs increased, the performance gradually dropped. These might have happened due to the behaviour of CNT nanomaterial, which is highly entangled products and difficult to disperse uniformly in fluids [11-12]. The suspension with stable condition may lead to better performance. Thus, the suitable de-agglomeration techniques for CNTs might be generating better dielectric fluid.

\subsection{Comparison of AC Breakdown Voltage at Various Gap}

Fig. 25 shows the behaviour of $1 \%$ probability of breakdown failure at three gap distances $(1.5 \mathrm{~mm}, 2.5 \mathrm{~mm}$ and $3.5 \mathrm{~mm})$ for six types of oil samples including mineral oil as a reference. 


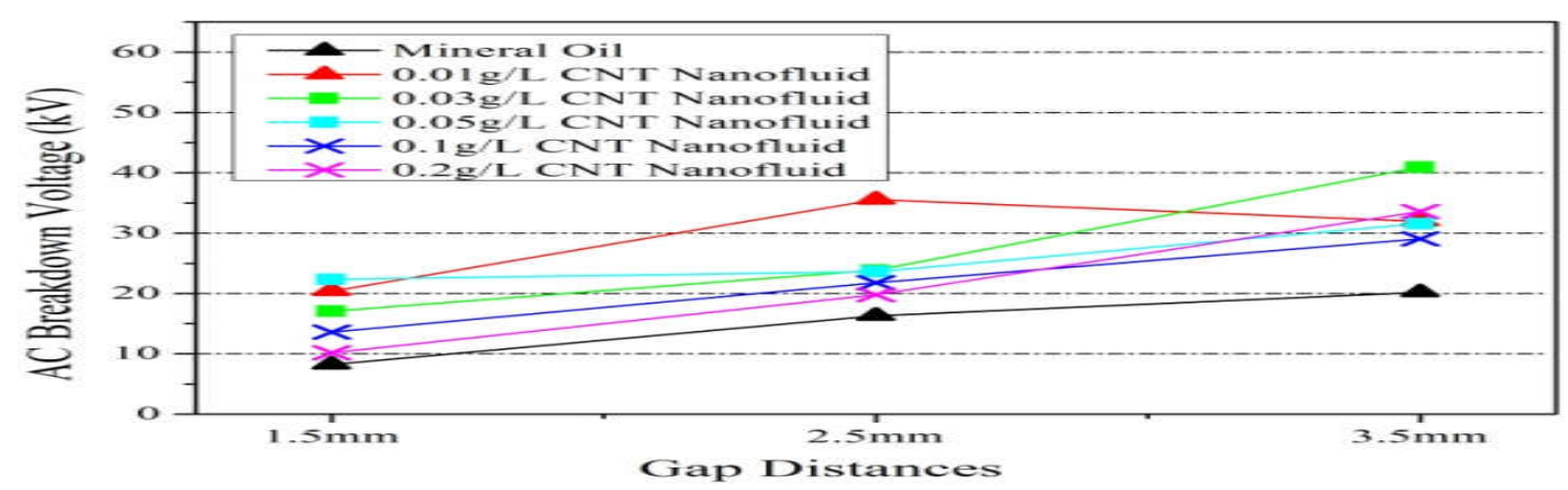

Fig.25. Probabilities of $1 \%$ breakdown failure of mineral oil and CNT nanofluids at three gap distances

The value of AC breakdown voltages for all types of oil increased along with gap distances except for $0.01 \mathrm{~g} / \mathrm{L} \mathrm{CNT}$ nanofluid. The trend of AC breakdown voltages showed in the graph were also agreed by other researchers [13]. However, in case of $0.01 \mathrm{~g} / \mathrm{L}$ CNT nanofluid concentration, the graph trends dramatically began to decrease from $2.5 \mathrm{~mm}$ to $3.5 \mathrm{~mm}$ gap distances. This might be due to the inconsistent dispersion behaviour of CNTs in mineral oil. In addition, the distinction behaviour of CNT nanofluid was consequences of the morphed electrodynamics within the oil caused by nanotubes, thereby produce different response from base mineral oil. Based on overall perspective, the concentrations of CNT nanofluid affect the value of breakdown voltages obtained. The amount of CNTs in mineral oil might affect the performances of AC breakdown voltages. The sound energy that applied into CNT nanofluid might not be enough due to larger amount of CNT nanofluid. Thus, CNT may not fully disperse and affect the stability of oil. However, based on $1 \%$ probability of breakdown voltage, all range of CNT nanofluids produced higher performance compare to Hyrax transformer mineral oil.

\section{CONCLUSION}

This paper shows the comparison between Hyrax mineral oil as reference transformer oil and five different concentrations of CNT nanofluids. The sonication technique has been used in order to disperse CNT nanomaterials in the mineral oil. AC breakdown voltage test was performed at three gap distances by following proper procedure according to IEC 60156 . Based on the experimental and statistical results, the following conclusions have been made: 
1) For $1.5 \mathrm{~mm}$ gap distance, all types of CNT nanofluids have enhance some improvement compare to mineral oil except for $0.2 \mathrm{~g} / \mathrm{L} \mathrm{CNT}$ nanofluid. As for $2.5 \mathrm{~mm}$ gap distance, $0.1 \mathrm{~g} / \mathrm{L}$ up to $0.05 \mathrm{~g} / \mathrm{L}$ CNT nanofluids achieved the same results except for $0.1 \mathrm{~g} / \mathrm{L}$ and $0.2 \mathrm{~g} / \mathrm{L}$ CNT nanofluids which have lower results compare to reference mineral oil. Lastly, for $3.5 \mathrm{~mm}$ gap distance, the breakdown voltage performances for all range of CNT nanofluids achieved higher results compare to mineral oil. Thus, it can be concluded that CNT nanofluids have huge potential to enhance the performances of breakdown voltage in transformer application.

2) The concentrations of CNT nanofluids increased affect the breakdown voltage performances. It can be considered that the agglomeration of nanotubes might happened when CNTs approaches saturation level, and lead to reduction of the withstand voltage capability. Some researchers investigated that some surfactants are possible to help modify the nanomaterials in the insulating oil.

Based on the Weibull distribution analysis, $1 \%$ probability of AC breakdown voltages in CNT nanofluids $(0.03 \mathrm{~g} / \mathrm{L}, 0.05 \mathrm{~g} / \mathrm{L}, 0.1 \mathrm{~g} / \mathrm{L}$ and $0.2 \mathrm{~g} / \mathrm{L})$ increased along with the gap distances from $1.5 \mathrm{~mm}$ to $3.5 \mathrm{~mm}$. The behaviour of CNT nanofluids breakdown voltages were figure out to be similar to the pattern of mineral oil. However, different cases for $0.01 \mathrm{~g} / \mathrm{L} \mathrm{CNT}$ nanofluid which having fluctuated trend. The dispersion behaviour of CNTs in mineral oil might affect the stability of nanofluid and causes performance to drop at $3.5 \mathrm{~mm}$ gap distance.

\section{ACKNOWLEDGEMENTS}

The authors would like to thank Ministry of Education and National Defence University of Malaysia for the funding under FRGS scheme (FRGS/2/2014/TK03/UPNM/02/2), (FRGS/1/2015/SG06/UPNM/03/3) and RAGS scheme (RAGS/1/2014/TK03/UPNM/1).

\section{REFERENCES}

[1] Choi S U S, Eastman J A. Enhancing thermal conductivity of fluids with nanoparticles. In ASME International Mechanical Engineering Congress and Exposition, 1995, pp. 99-105

[2] US Research Nanomaterials. Aluminum oxide $\left(\mathrm{Al}_{2} \mathrm{O}_{3}\right)$ nanopowder/nanoparticles 
dispersion $\left(\mathrm{Al}_{2} \mathrm{O}_{3}\right.$ nanoparticles aqueous dispersion, Alpha, $\left.20 \mathrm{wt} \%, 30 \mathrm{~nm}\right)$. Texas: US Research Nanomaterials, Inc., 2017

[3] Li S, Karlsson M, Liu R, Ahniyaz A, Fornara A, Salazar-Sandoval E J. The effect of ceria nanoparticles on the breakdown strength of transformer oil. In IEEE 11th International Conference on the Properties and Applications of Dielectric Materials, 2015, pp. 289-292

[4] Du Y F, Lv Y Z, Jian-Quan Z, Li X X, Li C R. Breakdown properties of transformer oil-based $\mathrm{TiO}_{2}$ nanofluid. In IEEE Annual Report Conference on Electrical Insulation and Dielectric Phenomena, 2010, pp. 1-4

[5] Kaushik B. K., Majumder M. K. Carbon nanotube based VLSI interconnects: Analysis and design. New Delhi: Springer, 2015

[6] Endo M, Hayashi T, Kim Y A, Muramatsu H. Development and application of carbon nanotubes. Association of Asia Pacific Physical Societies Bulletin, 2008, 18(1):1-11

[7] Madni I, Yu S, Sun R. Carbon nanotubes based composites with high dielectric constant and low loss. In IEEE 14th International Conference on Electronic Materials and Packaging, 2012, pp. 1-6

[8] International Electrotechnical Commission (IEC). Insulating liquids-Determination of the breakdown voltage at power frequency-Test method. Geneva: IEC, 1995

[9] Rinne H. The Weibull distribution: A handbook. Florida: CRC Press, 2008

[10] Abernethy R. B. The new Weibull handbook fifth edition, reliability and statistical analysis for predicting life, safety, supportability, risk, cost and warranty claims. Robert B. Abernethy, 2006

[11] Hilding J, Grulke E A, George Zhang Z, Lockwood F. Dispersion of carbon nanotubes in liquids. Journal of Dispersion Science and Technology, 2003, 24(1):1-41

[12] Mao C, Zou H, Zhou X, Huang Y, Gan H, Zhou Z. Analysis of suspension stability for nanofluid applied in minimum quantity lubricant grinding. International Journal of Advanced Manufacturing Technology, 2014, 71:2073-2081

[13] Mansor N S, Kamarol M, Azmi K. Breakdown voltage characteristic of biodegradable oil under various gap of quasi-uniform electrode configuration. In IEEE International Conference on Power and Energy, 2012, pp. 732-735 
[14] Sauki N S, Muhamad N A, Zahid F S, Herman S H, Rizman Z I. The structural and electrical properties of nanostructures $\mathrm{ZnO}$ thin films on flexible substrate. International Journal on Advanced Science, Engineering and Information Technology, 2017, 7(3):822-828

\section{How to cite this article:}

Suhaimi NS, Ishak MT, Din MF, Ariffin MM, Razali S, Amin NA,. Hashim FR. Breakdown strength of transformer oil filled with carbon nanotubes under various gap distances. J. Fundam. Appl. Sci., 2017, 9(3S), 41-60. 